\title{
Needs Assessment Approach To Product Bundling In Banking Enterprise
}

\author{
Shreyas Suresh Rao, Salma Banu N K, Sowjanya Lakshmi A \\ Computer Science \& Engineering Sir M Visvesvaraya Institute of Technology Bangalore, India
}

\begin{abstract}
In this paper, we propose a needs assessment based approach to achieve product bundling in a retail banking enterprise setup. Product bundling involves grouping together different products/ services belonging to the samel different lines of business in a bank and offering the bundle to the customer of the bank. The proposed approach helps banks understand the needs of the customer and recommend product bundles. Needs Assessment should be accessible across all the delivery channels of the bank. The paper proposes a multi layered architecture to achieve the same.
\end{abstract}

Keywords: needs assessment, product bundle, banking enterprise, multi layered architecture

\section{Introduction}

Banking enterprise comprises of various lines of businesses (LOBs) like Retail, Business Banking \& Commercial. Each LOB offers various products/ services to bank's customers. The scope of the paper is with respect to retail banking.

The challenges in banking industry are forcing banks to renovate their core systems to survive fierce competition. [1]

Traditionally, banks sell one or more products to customers based on the needs of the customers. A recent approach to increase revenue in banks is to bundle different products \& sell them as a package to the customer.

Banks are always seeking more flexible and efficient ways to package and price their products in order to attract new customers and sell more products to their existing customers. In addition, the economic downturn has brought a greater focus on efficiency and cost reduction. [2]

To successfully achieve customer-centric initiatives, while at the same time reducing costs, banks must invest in enterprise product agility.

Product agility is the ability to sense market changes and rapidly react to those changes by bringing the right product bundles to market at the right time.

There are significant results for online banking offerings within product bundling. Wells Fargo indicated 50\% less attrition of customers and Bank of America indicated 55\% less attrition of customers due to product bundling. [3]

A Customer is a client of the bank who already has a relationship with the bank i.e., has one or more products of the bank. A prospect is a potential customer who is yet to have a relationship with the bank.

Product Bundling is the process of grouping different products/services of the bank within/ across different LOBs \& offering the bundle to the customer/ prospect. Bank gains from this by being able to sell/cross-sell more products to a single customer \& customer gains by getting discounted rates for the bundle products as compared to their individual product prices.

This paper provides an insight into the precursor activity to product bundling which shall consist of the following steps:

- Needs Assessment where the bank understands the needs of the customer.

- Analysis of the Needs Assessment (Business logic to perform analysis).

- Recommendation of different products/ services to the customer to create a bundle.

- Selection of products to create a new product bundle.

The above mentioned activities must be available across all the different delivery channels of the bank i.e Internet banking, Mobile banking, Branch, Bank website etc.

At this stage, Customer selects a custom product bundle after the needs assessment.

Next activity:

Creation of the custom product bundle - this stage involves the activities needed to create a new product bundle. This stage is out of scope in this paper. 
II. Stages of Needs Assessment

The stages of needs assessment are given below: (Also depicted in figure1)

\section{A. Needs Assessment Questionnaire} creation.

In this stage, the bank understands the needs of the customer with respect to custom product bundle

A set of questions shall be asked to the Prospect/ Customer which forms the basis of needs assessment.

The questions shall be categorized for Prospect and Customer.

The categories shall be:

- Personal questions for the Prospect to capture their profile details.

- Bundle related questions for both Prospect and Customer.

The Prospect/ Customer answer the questions in the needs assessment questionnaire and submit the questionnaire.

Customer can save the needs assessment midway across any of the channels and later come back to reaccess the saved needs assessment and continue.

\section{B. Analysis of the Needs Assessment}

Business rule defines or constraints one aspect of business i.e., intended to assert business, structure or influence the behaviour of business. [4]

Once the customer submits the needs assessment questionnaire, analysis of the needs shall be done based on a set of business rules which map the customer selected answers to pre-existing business rules.

C. Recommendation of Products

Customer is presented the list of products/ services represented in the retail product bundle to create custom bundle based on the needs assessment.

The list includes:

- Products which are recommended by Needs Assessment analysis.

- Un-recommended products - which are not recommended by needs assessment analysis but can be eventually selected by the customer for custom bundle.

- Products/ services already owned by the customer

- The products shall be further classified as "Mandatory" and "Optional" products. Mandatory products are always recommended.

\section{Selection of products by Customer}

Customer can select products which are new or existing (which customer already has) to create custom product bundle.

Mandatory products have to be selected and optional products may/may not be selected.

\section{High Level Architecture}

Architecture shall be a Multi-Layered architecture with Service Orientation. Service orientation provides the ability to integrate disparate solutions more easily. [5] High Level Architecture is depicted in Figure 3.

The following shall be the different layers of the architecture:

\section{A. Presentation Layer}

'This layer contains the user interface components and presentation logic for the application. The user interface components cater to the different delivery channels like Internet banking, Mobile banking, Branch, Bank website which have different software requirements. The Customer (through Internet or mobile banking or bank website) or Bank user (through branch) shall access this layer.

\section{B. Business Layer}

This layer acts as an application facade which redirects the received requests from Presentation layer to appropriate Service layer or Data layer requests.

\section{Service Layer}

This layer shall consist of various business level services used for needs assessment. The important aspect of using business services is reusability [6]. The same services can be reused, if, in the future needs assessment needs to be done for business banking or commercial lines of business.

The following are some of the business level services identified: 
- Needs Assessment Service - Shall be an umbrella/ composite service to retrieve questionnaire for needs assessment and for submission of needs assessment answers.

- Business Rules Service

- Recommendation Service - Shall provide the recommended/ un-recommended/ existing customer products based on the needs assessment carried out.

D. Service Integration Layer

This layer comprises of existing banking services for retail line of business. The Services layer shall interact with this layer to extract existing customer profile information or product information. [7]

\section{E. Data Layer}

This layer contains the data access capabilities of the needs assessment system and interacts with data sources and external systems of retail banking.

\section{F. Cross Cutting Concerns Layer}

This layer contains the common utilities that are required for the entire application (needs assessment and product bundling applications)

The common utilities are:

- Authentication and Authorization - based on the delivery channel requirements

- Security - based on the delivery channel requirements

- Logging - includes application and exception logging

\section{Business Rules}

- A business rules engine/ XML shall be designed which contains mapping between the answers of needs assessment and the products to be recommended for the same.

- The analysis will be done for the needs assessment based on the rules in the rules engine/XML file.

- A business rules service shall be designed for this job.

\section{Database Architecture:}

Below is briefly explained the logical entities of needs assessment. Description is provided only for selected entities and attributes.

Entity relationship (ER) diagram is provided in Figure 2.

\begin{tabular}{|l|l|}
\hline \multicolumn{2}{|c|}{ NeedsAssessmentType } \\
\hline \multicolumn{1}{|c|}{ Attribute Name } & \multicolumn{1}{c|}{ Description } \\
\hline NeedsAssessmentTypeId & Unique Identifier \\
\hline NeedsAssessmentTypeName & $\begin{array}{l}\text { Uniquely identifies the type } \\
\text { of Needs Assessment. }\end{array}$ \\
\hline
\end{tabular}

\begin{tabular}{|l|l|}
\hline \multicolumn{2}{|c|}{ NeedsAssessmentVersion } \\
\hline \multicolumn{1}{|c|}{ Attribute Name } & \multicolumn{1}{c|}{ Description } \\
\hline NeedsAssessmentVersionId & Unique Identifier \\
\hline NeedsAssessmentTypeId & $\begin{array}{l}\text { Foreign key reference to } \\
\text { NeedsAssessmentType } \\
\text { entity }\end{array}$ \\
\hline Version & $\begin{array}{l}\text { Version of needs } \\
\text { assessment }\end{array}$ \\
\hline EffectiveDate & $\begin{array}{l}\text { Effective date of needs } \\
\text { assessment version }\end{array}$ \\
\hline ExpiryDate & $\begin{array}{l}\text { Expiry date of needs } \\
\text { assessment version }\end{array}$ \\
\hline
\end{tabular}

\begin{tabular}{|l|l|}
\hline \multicolumn{2}{|c|}{ NeedsAssessmentData } \\
\hline \multicolumn{1}{|c|}{ Attribute Name } & \multicolumn{1}{c|}{ Description } \\
\hline NeedsAssessmentDataId & Unique Identifier \\
\hline CustomerId & $\begin{array}{l}\text { Reference of Customer who is } \\
\text { doing needs assessment }\end{array}$ \\
\hline
\end{tabular}


Needs Assessment Approach to Product Bundling in Banking Enterprise

\begin{tabular}{|l|l|}
\hline \multicolumn{2}{|c|}{ NeedsAssessmentData } \\
\hline Attribute Name & \multicolumn{1}{c|}{ Description } \\
\hline Status & $\begin{array}{l}\text { Status of needs assessment } \\
\text { Channel through which needs }\end{array}$ \\
\hline Channel & \\
\hline
\end{tabular}

\begin{tabular}{|c|l|}
\hline \multicolumn{2}{|c|}{ Customer } \\
\hline $\begin{array}{c}\text { Attribute } \\
\text { Name }\end{array}$ & \multicolumn{1}{|c|}{ Description } \\
\hline CustomerId & Unique Identifier \\
\hline PanNumber & $\begin{array}{l}\text { Uniquely identifies the } \\
\text { customer }\end{array}$ \\
\hline
\end{tabular}

\begin{tabular}{|l|l|}
\hline \multicolumn{2}{|c|}{ Product } \\
\hline \multicolumn{1}{|c|}{ Attribute Name } & \multicolumn{1}{c|}{ Description } \\
\hline ProductId & Unique Identifier \\
\hline ProductName & Name of the Product \\
\hline NeedsAssessmentTypeId & $\begin{array}{l}\text { Reference to } \\
\text { NeedsAssessmentType } \\
\text { entity }\end{array}$ \\
\hline
\end{tabular}

\begin{tabular}{|l|l|}
\hline \multicolumn{2}{|c|}{ RecommendationData } \\
\hline \multicolumn{1}{|c|}{ Attribute Name } & \multicolumn{1}{c|}{ Description } \\
\hline RecommendationDataId & Unique Identifier \\
\hline NeedsAssessmentDataId & $\begin{array}{l}\text { Reference to Needs Assessment } \\
\text { Data entity }\end{array}$ \\
\hline ProductId & $\begin{array}{l}\text { Reference to Product entity. } \\
\text { Recommended product by the } \\
\text { system }\end{array}$ \\
\hline
\end{tabular}

\begin{tabular}{|l|l|}
\hline \multicolumn{2}{|c|}{ ProductSelectionData } \\
\hline \multicolumn{1}{|c|}{ Attribute Name } & \multicolumn{1}{c|}{ Description } \\
\hline ProductSelectionDataId & Unique Identifier \\
\hline NeedsAssessmentDataId & $\begin{array}{l}\text { Reference to Needs Assessment } \\
\text { Data entity }\end{array}$ \\
\hline ProductId & $\begin{array}{l}\text { Reference to Product entity. } \\
\text { Selected Product by the } \\
\text { customer }\end{array}$ \\
\hline
\end{tabular}

IV. Figures

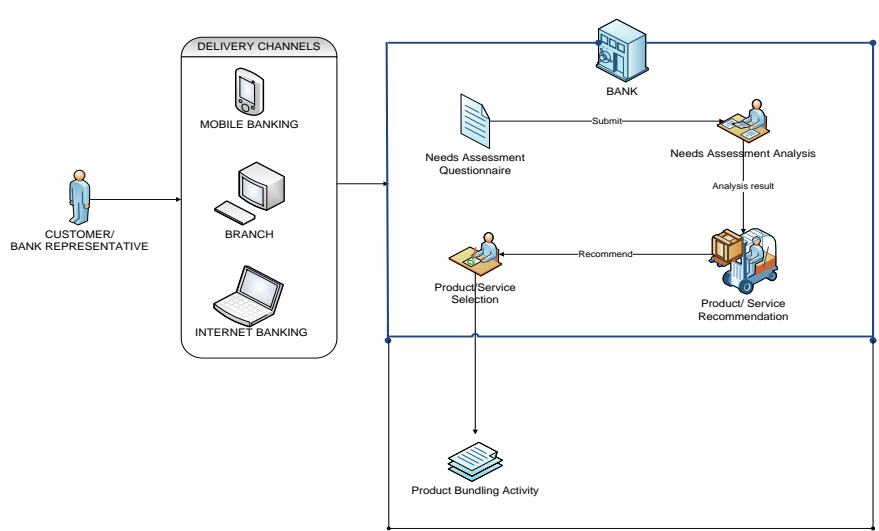

Figure 1: Pictorial representation of the Needs Assessment System. The highlighted boundary in 'blue' indicates the scope of this paper. 


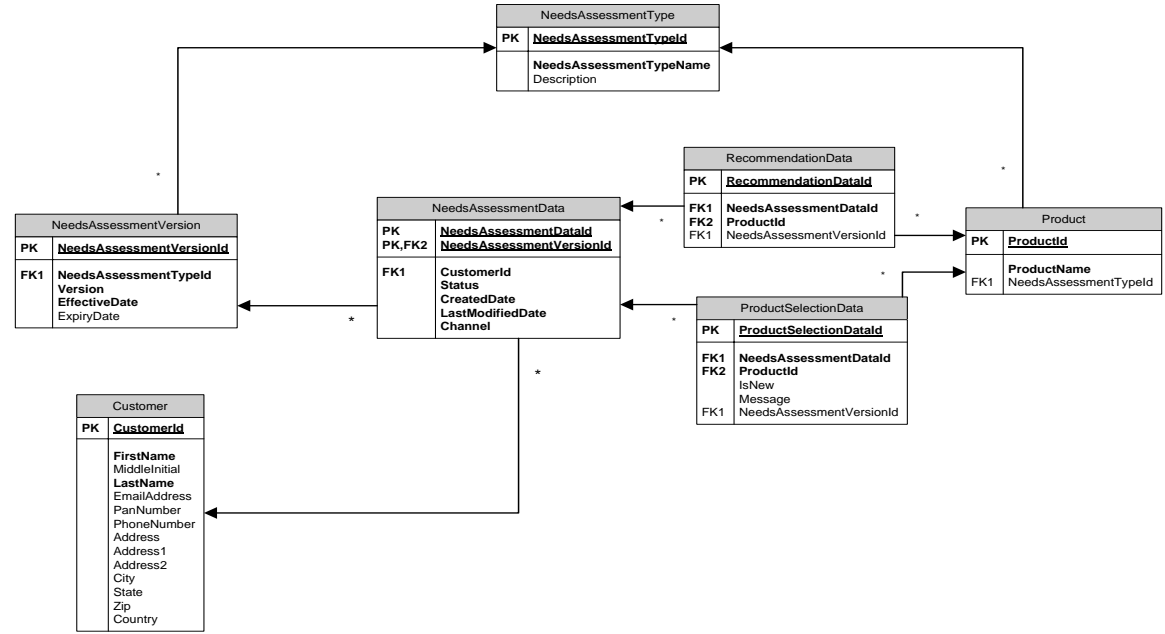

Figure 2: Logical Entity-Relationship diagram of Needs Assessment

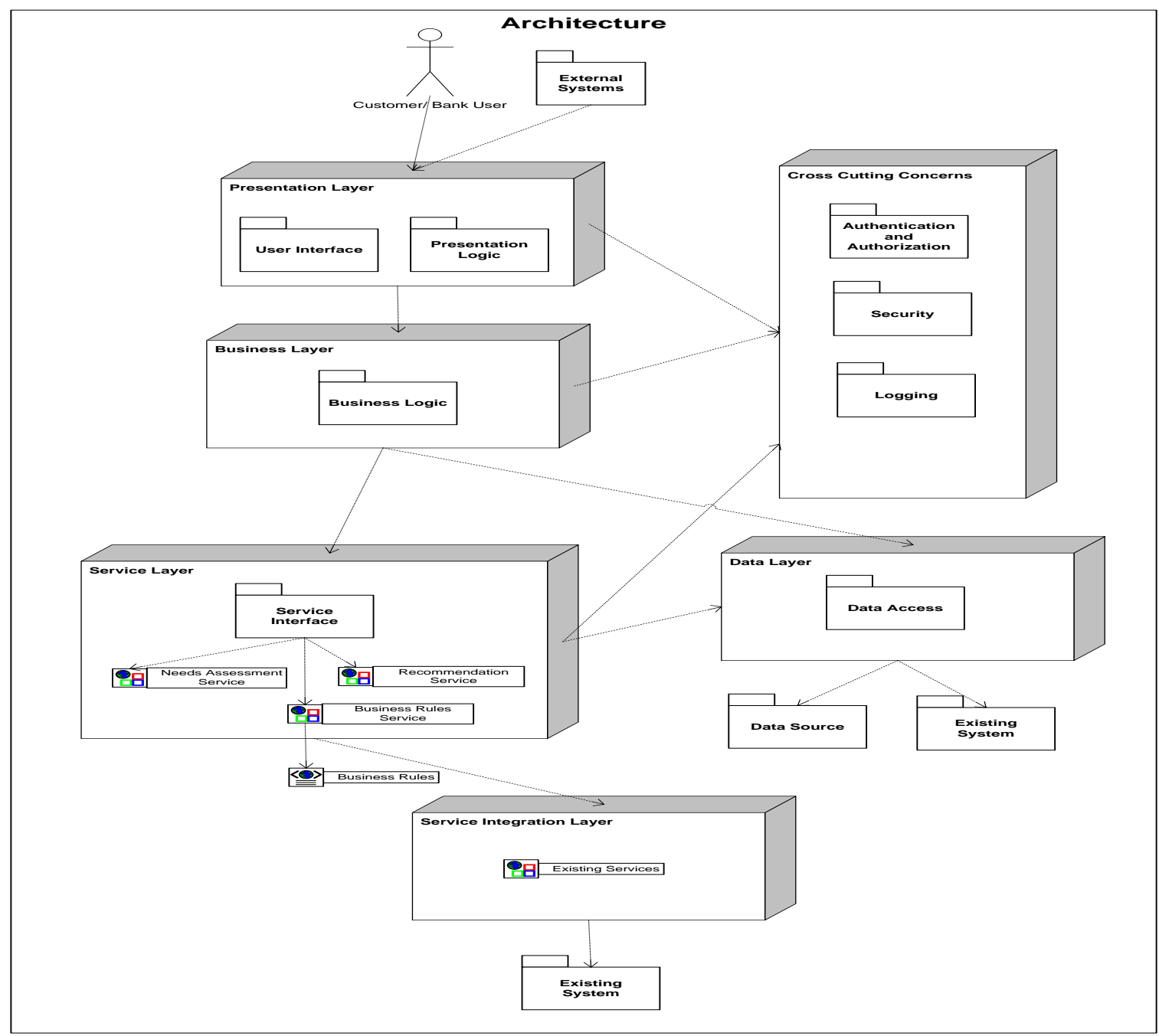

Figure 3: Depicts the Needs Assessment High Level Architecture

\section{Assumptions/ Dependencies}

- The Needs Assessment approach is limited to "Retail" Line of Business.

- The Product Bundle contains a fixed set of retail products and is not modifiable.

- Customer's profile and product information is maintained in some database/ datawarehouse within the retail banking. 
- Focus is on needs assessment for bundle creation and not on existing bundle maintenance.

- The term "Existing Products" refers to the set of retail products already owned by the customer.

- Retail Line of Business has services which already have been built and interact with existing systems to retrieve customer and product related information.

\section{Conclusion}

This paper provides details on a needs assessment based approach to custom retail product bundling in a banking enterprise setup. It includes the different stages of needs assessment, proposes a high level architecture (layered and service oriented) needed to realise the needs assessment requirement.

Future work to this paper can include:

- Extending the requirements to include other Lines of Business like Business Banking and Commercial.

- Detail the requirements and architecture for existing product bundle maintenance using needs assessment.

\section{References}

[1] Rong Liu, Frederick Wu, Yasodhar Patnaik, Santosh Kumaran, "Business Entities: An SOA Approach to progressive core banking renovation,", scc, pp.466-473,2009 IEEE International Conference on Services Computing, 2009.

[2] Camilion Solutions, "Enterprise Product Agility enables Dynamic Product Bundling", 2010.

[3] Brian King, BenchMark Consulting International, "Consumer Lending Cross-Sell and Product Bundling”, July 2006.

[4] ERIC RIES, “The Lean Startup: How Today's Entrepreneurs use continuous innovation to create radically successful business", September 13, 2011.

[5] Christine Barry, Oracle Financial Services, "Core Banking replacements and the benefits of service-oriented architectures", Oracle White Paper, January 2009.

[6] Eswar Ganesan, Ramesh Paturi, "Building Blocks for Enterprise Business Architecture”, SETLabs briefings, VOL 6, NO 4, 2008

[7] Srinivasan M S, Gnanapriya C, "Transformation of Enterprise Product Management for Rapid Launch of Next Generation Products", Infosys White Paper, March 2009. 